\title{
A Review of the Literature on Enterprise Mentoring: A Perspective of Social Capital Theory
}

\author{
Min Shen \\ School of Management, Jinan University, Guangzhou, China \\ Email: min_29976@163.com
}

How to cite this paper: Shen, M. (2020) A Review of the Literature on Enterprise Mentoring: A Perspective of Social Capital Theory. Open Journal of Business and Management, 8, 892-901. https://doi.org/10.4236/ojbm.2020.82055

Received: March 1, 2020

Accepted: March 22, 2020

Published: March 25, 2020

Copyright $\odot 2020$ by author(s) and Scientific Research Publishing Inc. This work is licensed under the Creative Commons Attribution International License (CC BY 4.0).

http://creativecommons.org/licenses/by/4.0/

\begin{abstract}
Enterprise mentoring is an important means of helping employees to gain career success and is also one of the important research topics in organizational behavior. From the perspective of social capital theory, this paper reviews and summarizes the research papers on enterprise mentoring from the two ways of network structure indicators and social resources indicators. It also points out the shortcomings of the current situation and possible directions of future research.
\end{abstract}

\section{Keywords}

Enterprise Mentoring, Mentor Network, Social Capital, Mechanism of Enterprise Mentoring

\section{Introduction}

Han Yu's "On Teachers" says, "A teacher is one who passes on the truth, imparts knowledge and solves puzzles." It can be seen that the mentor-student relationship has existed since ancient times, not a modern product, and has a history of thousands of years. At first, the mentoring system was implemented in the education industry. Both sides of the system referred to teachers and students. As the mentoring became more mature, it was introduced in all walks of life, especially for skilled workers. The industries with great demand and the positions that need a lot of tacit knowledge, such as haircutting, repairing, textile, and scientific research, are all inseparable from the operation and maintenance of the mentoring.

After experiencing the silence of the mentoring in the 1980s, and with the rapid development of information today, the enterprise mentoring has regained 
vitality. With the development of the sharing economy and "Internet+", human capital dividends have become apparent, employees have become more eager for knowledge and growth, and companies have paid more attention to the cultivation and shaping of employees. Therefore, as an important means of selecting talents and cultivating personal capabilities, enterprise mentoring has been widely welcomed by many companies. Ensher and Murphy (2005) conducted interviews and surveys with 50 US executives and found that almost all executives have a "one-to-one" or "many-to-one" relationship with a strong mentor consulting team [1]. This not only indicates the importance and necessity of the enterprise mentoring, but also indicates that the relationship between mentors and apprentices will develop into a complex network structure in the future. Zhou et al. (2009) found that the social capital of the staff mentor network has a significant impact on the effectiveness of the mentor network and the level of mentor network effectiveness is positively related to the employee's career success [2]. Xu and Liang (2015) also did empirical research and confirmed that a good mentoring relationship can significantly improve the subjective and objective success of employees [3]. All this shows that enterprise mentoring is of great value to the companies and employees. Therefore, this topic has been popular in the section of organizational behavior since the $21^{\text {st }}$ century.

So what is the enterprise mentoring? How does the master-student relationship form? What effect does it have? Through Web of Science, it was found that studies on mentoring originated in the 1980s, and they had in-depth research on the concept, types, formation, mediation variables, moderating variables, and benefits of mentoring. This article only reviews the enterprise mentoring from the perspective of social capital theory, in an attempt to lay a certain research foundation for scholars and give some suggestions to practitioners.

\section{Enterprise Mentoring and Social Capital}

\subsection{Enterprise Mentoring}

There are many definitions of enterprise mentoring at home and abroad. The more classic one is the definition made by Kram (1985), that is, enterprise mentoring refers to the relationship between the senior mentor and the supervised protégé. Or is it a relationship between peers that can provide psychological support and career guidance to gain personal success and organizational identity. This is the original "one-to-one" dualistic relationship between master and apprentice, which plays a role in both career-related function and psychological function (Kram, 1985) [4]. Career guidance refers to the master teaching the apprentice the skills, efficient methods and experience required by work, and helping the apprentice to rationally plan his career development. Psychological support is that the master helps the apprentice build cooperation, trust, and mutual care with others, provides affirmations at work, and assists students in building self-confidence in solving work problems independently and sense of responsibility and belonging to the organization. 
As the economy develops and the economic situation becomes more and more complicated, one mentor seems to become insufficient. The concept of "multiple mentors" has emerged, and the "one-to-one" dual relationship has gradually developed into a "one-to-many" or "many-to-one" mode. It is found that "multi-mentors" also has a promotion effect on apprentices' job performance, career planning, and organizational commitment. And the function of mentoring is no longer limited to vocational guidance and psychological support. Scandura (1992) believes that the master is an example for the apprentice, so role modeling is also used as one of the mentoring functions. The role model refers to the master setting a good example for the apprentice with his own working ability, behavior and moral principles [5].

Higgins et al. (2010) pointed out that today's domestic and international economic and workplace situations have undergone major changes, and "borderless occupations" and variability have become the characteristics of today's workplace that cannot be ignored [6]. In order to adapt to such changes, the linear and tree-like mentorship has not been able to meet the needs of the workplace (Dobrow, 2012) [7], and the concept of "mentor network" came into being. The "Mentor network" looks at the relationship between mentors and students and the relationship between mentors and mentors from the perspective of social capital. It is defined as a group of mentors who can provide professional guidance and psychological support to students in their own social networks through introducing potential opportunities and passing on human capital (Janasz et al., 2003; Zhang, 2013) [8] [9]. The mentoring relationship builds a connected social network and forms a structural social capital. The network works because there exist many weak ties and structural holes. Relative to the dualistic mentorship and the concept of multiple mentors, "Mentor network" extends the enterprise mentorship to the perspective of social networks, reflecting the trend of mentoring and apprenticeship towards dynamic and networked development.

\subsection{Social Capital}

\subsubsection{The Definition of Social Capital}

Since Bourdieu introduced the concept of "social capital" into sociology, social capital theory has really begun to shine. Scholars in different fields have defined the connotation of social capital. Generally speaking, there are four representative types in the academic world: First, theory of social structure. Social capital is defined according to their function. They are composed of the various elements that make up the social structure and facilitate individual actions within the structure (Coleman, 1990) [10]. Second, theory of organizational characteristics. Social capital refers to the characteristics of social organizations, such as trust and norms, which can improve social efficiency by promoting coordinated actions (Putnam, 1993) [11]. Third, ability theory. Social capital refers to an individual's ability to mobilize scarce resources in a network or wider social structure (Alejandro Portes, 1996) [12]. The last is relationship resources theory. So- 
cial capital is a collection of various resources, and the opportunity to use resources and capital can be obtained by occupying a certain network structure (Burt, 1992; Nahapiet, Ghoshal, 1997) [13] [14].

There are two kinds of connotations of enterprise-level social capital. One is from the theory of capabilities (Alejandro Portes, 1995; Bian, Qiu, 2000; Wei, 2007) [12] [15] [16], the other is derived from the resource theory (Nahapiet, Ghoshal, 1997; Leenders, Gabbay, 1999) [14] [17]. The most classic and generally accepted is the definition proposed by Nahapiet and Ghoshal, that is, embedded and available resources derived from the inherent and potential resources of social networks owned by individuals or social units. Social capital is divided into three dimensions: structural dimension, relational dimension, and cognitive dimension, which provides a clear research framework for empirical research.

\subsubsection{The Main Theory of Social Capital}

Social capital theory mainly includes weak ties theory (Granovetter, 1973), structural hole theory (Burt, 1992), and social resource theory (Lin et al., 1981) [18] [13] [19]. Weak tie is the opposite of strong connection, which refers to the connection that is generated through social contacts in social networks, but the interaction frequency is low and the intimacy is low. It plays an important role in the social structure and can create the shortest path and speed up the speed at which information is transmitted between different groups. Besides, individuals tend to have direct connections with certain nodes in social networks and indirect connections with other nodes. The phenomenon of indirect connections means the existence of structural holes, which represents non-redundant connections in social networks. At the same time, structural holes play an important bridging role. Occupying more structural holes means occupying more social capital. The last, social resources theory is proposed by Lin Nan et al. He believes that social resources are embedded in the individual's social network and exist in the relationship between people. They must be obtained through contact and interaction, emphasizing the diversity and importance of the resources obtained by individuals. Weak ties and structural holes are indicators of social network structure which can be used to examine the relationships between individuals and other departments or other people. Social resource is an indicator of social network benefits. It examines the difficulty of obtaining resources and shelter in the workplace.

\section{The Mechanism of Enterprise Mentoring}

Many scholars have studied the intermediary mechanism of enterprise mentoring, which mainly divided into four perspectives of social learning theory, social exchange theory, social identity theory, and social capital theory. Social learning theory explains the role of enterprise mentoring through knowledge sharing and self-efficacy, especially the positive impact on disciples' career planning, job satisfaction, and organizational commitment (Han et al., 2013; Li, Wang, 2013; Li, Guo, 2017) [20] [21] [22]. Social exchange theory starts from the material and 
spiritual exchange between the master and the apprentice, and elaborates the role of the apprenticeship between the master and the apprentice. This kind of studies mainly pays attention to apprentice's influence on the master, but there is a lack of research literature on the organizational level (Ragins, Scandura, 1999; Feeney, Bozeman, 2008) [23] [24]. Social identity theory mainly explains the mechanism of enterprise mentoring between self-identification and team identification. Most of the literature focuses on the "one-to-one" dual mentoring relationship, but deep research on organizational identity is still few (Ellemers et al., 2004) [25]. From the perspective of social capital theory, the mentor-apprentice relationship breaks through the "one-to-one" pairing model and develops into a more complex social network, thereby it is possible to master certain structural or cognitive social capital. At the same time, the existing literature pays more attention to the influence of mentoring on apprentices, and research is mostly limited to the individual level (Han, Yang, 2012; Xu, Liang, 2015; Carter, Youssef-Morgan, 2019) [26] [3] [27].

Taking enterprise mentoring as the antecedent variable, career success and organizational effectiveness as the outcome variables, this article sorts out the mediating variables from the perspective of social capital theory, and attempts to unveil the mechanism of enterprise mentoring from social capital perspective for everyone.

\subsection{Network Structure Indicators}

Based on the theory of weak ties and structural holes, many scholars have introduced the theory of social capital into organizational behavior and studied the intermediary mechanism of enterprise mentoring in an attempt to unveil the influence path of the mentor network from the perspective of social capital.

Some scholars have found that some structural indicators of the mentor network are significantly related to employees' job performance, career satisfaction, and organizational commitment. Zhou et al. (2009) found through empirical analysis that tie strength of the employee's mentor network has a significant positive correlation with the benefits that employees receive from the mentor network. The level of occupational support and psychological support obtained is measured, and these two network benefit variables are positively related to employee salary levels and promotion times, and significantly positively related to professional satisfaction [2]. Hassan et al. (2017) also conducted research and analysis based on questionnaire data of female faculty members of Nigerian universities, and reached similar conclusions, arguing that social capital variables, especially the level of tutoring system, network level and government agencies, are the important factors for the promotion of female faculty members of Nigerian universities. The empirical model has confirmed the role of social capital in enterprise mentoring [28]. Not only is the mentor-student relationship in the actual work environment affecting the disciples' professional success and organizational effectiveness, the E-mentoring network has also attracted scho- 
lars' attention. After research, it is found that the quality of the relationship has a positive impact on job self-efficacy, increasing adolescents' objective expectations of careers (DiRenzo et al., 2013) [29]. Dong et al. (2014) used 252 new recruits from a public copper smelting company in China as a sample to examine the relationship between enterprise mentoring and career success under different social network densities. It is found that the strength of the mentor team is positively related to job satisfaction. Besides, the network density moderates the relationship between the strength of the mentor team and job satisfaction, that is, the relationship is positive when the network density is low, and negative when the network density is high [30].

In addition, based on the above research results, some scholars have explored how to establish a high-level, high-quality mentor-apprentice relationship. Kim Seong-Kook et al. (2007) believe that the personal characteristics of disciples will affect the structural characteristics of the mentor network, such as self-monitoring tendency has an impact on the tie strength of the mentor network [31]. Rochelle et al. (2013) emphasized the importance and necessity of establishing a mentor network, and argued that the dual relationship cannot meet the changing and complex professional situation [32] Lee et al. (2012) believes that the similarity between disciples and mentors and the degree to which disciples are willing to open to the mentor network will affect the effective establishment of the mentor network [33].

At the same time, there are a few scholars who believe that the structural characteristics of the mentor network are limited and cannot significantly affect the personal success and organizational effectiveness of the disciples. Nikos Bozionelos and Li Wang (2006) conducted research in the Chinese context and concluded that the relationship between social capital and career success is limited. Specifically, the number of employees' mentors is related to their internal career success, but has nothing to do with their external career success. Besides, the number of ties has nothing to do with both internal and external career success [34].

\subsection{Social Resources Indicators}

The social capital brought by the enterprise mentoring undoubtedly has an impact on the professional success and organizational effectiveness of the apprentices. In addition to the network structure indicators of the mentoring system, it can also be explained from the social resource theory proposed by the scholar Lin Nan. The mechanism is as follows: In the enterprise mentoring system, the mentor and apprentice form a crisscross social network. The mentor uses his own social network to help the apprentice to establish his own network of contacts, thereby mastering more social relationships and social resources, and receiving professional and psychological support to get professional success.

In the employee's mentor network, the social resources of the mentor are positively related to the professional and psychological support received by the 
employee, thereby enhancing the employee's professional satisfaction level (Zhou et al., 2009) [2]. When there are mentors in the mentor network who are outside the organization, the mentors can bring a lot of and diverse social relationships to the apprentice, which can bring more job opportunities and useful information to the apprentice, and increase the apprentice's exposure probability (Feeney, Bozeman, 2008) [24]. Viator and Dalton (2011) take the specific profession of CPA as an example. It is recommended that CPA professionals seek more familiar and advanced managers or partners, establish a variety of guiding relationships, and obtain richer social resources. More professional and psychological support also makes it easier to obtain career success and promotion [35]. Gayle et al. (2005) did a more in-depth study and found that the density of the mentor network in the early career of employees is negatively related to professional identity and job satisfaction. The reason is that the sparser the mentor network is, the less redundant the social relationships and resources provided by mentors are. It means that apprentices are more likely to achieve professional success [36]. These findings support the notion that social resources have a positive effect on career success. In the Chinese context, due to the particularity of Chinese culture, Nikos Bozionelos and Li Wang (2006) have concluded that they are completely inconsistent with traditional cognition. They found that there is no significant relationship between the social resources of the mentor network and the internal and external professional success of employees.

\section{Summary and Future Outlook}

After sorting out the above, this paper finds that from the perspective of social capital theory, domestic and foreign research literature on enterprise mentoring starts from two aspects of network structure indicators and social resource indicators, and explores the influencing mechanism of social capital of the enterprise mentoring on professional success and organizational effectiveness.

From the perspective of social capital theory, the research still has some shortcomings. First, this paper mainly focuses on the positive impact of enterprise mentoring on apprentices' career success and psychological support, while less attention is paid to the negative impact on the apprentice. Second, most of the literature is limited to the individual level of employees, and lacks cross-level research on individual-team-organization. Therefore, in view of the actual situation and theoretical development, this paper believes that the future research of enterprise mentoring from the perspective of social capital theory may have the following trends:

First, make more empirical research on the negative effects brought by enterprise mentoring to both mentors and apprentices. In the "one-on-one" dual apprenticeship, some scholars have also studied the negative effects of enterprise mentoring. For example, the black halo effect, that is, the exclusion and decline of the mentor in the enterprise will bring a lot of big negative effects to apprentices. Well, in the mentor network, the mentor failure theoretically can also 
greatly reduce the apprentice's social capital, and even fall into the political struggle of the enterprise. However, this area still lacks the support of empirical research. Whether the tutor network will bring negative effects to both the teacher and apprentice, and whether the negative effects are severely hit still need further empirical tests.

Second, the mediating variables from the perspective of social capital theory can be further enriched. At present, the mediating variables of this perspective are mainly the structural variables of the mentor network and the indicators of social resource efficiency, which are mainly tie strength, network density, and social resources. Indicators of centrality and network factions in social capital theory can also be considered, not only to study the relationship between the master and the apprentice, but also to consider whether the relationship between the master and the apprentice will affect the apprentice. For example, in the tutor network, there may be different factions in the mentor network, so the quality of vocational guidance, effectiveness of knowledge transfer, and career planning of apprentices may be affected, which is also a possible trend for future research.

Finally, pay more attention to cross-level research on individual-team-organization. In this perspective, the existing literature is mostly limited to the individual level, and few cross-level studies are conducted. However, in reality, the mentor network involves more employees, and the levels of employees are different. Turbulence and change of one person are likely to affect the stability of the entire mentoring system, while turbulence in small groups will affect the cohesion, centripetal force, and performance of the entire organization. Therefore, cross-level research will also be a direction for future research.

\section{Conflicts of Interest}

The author declares no conflicts of interest regarding the publication of this paper.

\section{References}

[1] Ensher, E.A. and Murphy, S.E. (2005) Power Mentoring: How Successful Mentors and Proteges Get the Most Out of Their Relationships. Jossey-Bass Inc., New York.

[2] Zhou, X.H., Liu, B.J., Wu, X.N. and Jie, M.M. (2009) Study on the Effects of Mentoring Network on Employee's Career Success. Chinese Journal of Management, 6 , 1486-1491.

[3] Xu, J. and Liang, J. (2015) The Development of Informal Mentoring and Its Influence on Employee Early Career. Management Review, 27, 98-108.

[4] Kram, K.E. (1985) Mentoring at Work: Developmental Relationships in Organisational Life. Administrative Science Quarterly, 30, 454-456.

https://doi.org/10.2307/2392687

[5] Scandura, T.A. (1992) Mentorship and Career Mobility: An Empirical Investigation. Journal of Organizational Behavior, 13, 169-174.

https://doi.org/10.1002/job.4030130206 
[6] Higgins, M., Dobrow, S.R. and Roloff, K.S. (2010) Optimism and the Boundaryless Career: The Role of Developmental Relationships. Journal of Organizational Behavior, 31, 749-769. https://doi.org/10.1002/job.693

[7] Dobrow, S.R., Chandler, D.E., Murphy, W.M., et al. (2012) A Review of Developmental Networks: Incorporating a Mutuality Perspective. Journal of Management, 38, 210-242. https://doi.org/10.1177/0149206311415858

[8] Janasz, S.C.D., Sullivan, S.E. and Whiting, V. (2003) Mentor Networks and Career Success: Lessons for Turbulent Times. The Academy of Management Executive, 17, 78-93. https://doi.org/10.5465/ame.2003.11851850

[9] Zhang, Z.T. (2008) Research on Enterprise Mentoring. Foreign Economics \& Management, 30, 35-41.

[10] Coleman, J.S. (1990) Foundations of Social Capital. Belknap Press of Harvard University Press, Cambridge, MA.

[11] Putnam, R.D. (1993) The Prosperous Community: Social Capital and Public Life. American Prospect, 13, 35-42.

[12] Portes, A. and Landolt, P. (1996) The Downside of Social Capital. American Prospect, 26, 18-21.

[13] Burt, R.S. (1992) Structural Holes. Harvard University Press, Cambridge, MA.

[14] Nahapiet, J. and Ghoshal, S. (1998) Social Capital, Intellectual Capital, and the Organizational Advantage. Academy of Management Review, 23, 242-266. https://doi.org/10.5465/amr.1998.533225

[15] Bian, Y.J. and Qiu, H.X. (2000) The Social Capital of Enterprises and Its Efficiency. Social Sciences in China, No. 2, 87-99.

[16] Wei, Y. (2007) Corporate Social Capital and Technological Innovation: An Empirical Research Based on Perspective of Absorptive Capacity. China Industrial Economy, No. 9, 119-127.

[17] Leenders, R.T.A.J. and Gabbay, S.M. (1999) Corporate Social Capital and Liability. Springer, New York. https://doi.org/10.1007/978-1-4615-5027-3

[18] Granovetter, M.S. (1973) The Strength of Weak Ties. American Journal of Sociolo$g y$, 78, 1360-1380. https://doi.org/10.1086/225469

[19] Lin, N. and Vaughn, E.J.C. (1981) Social Resources and Strength of Ties: Structural Factors in Occupational Status Attainment. American Sociological Review, 46, 393-405. https://doi.org/10.2307/2095260

[20] Han, Y., Zhou, J., Sun, X.X. and Yang, B.Y. (2013) The Effect and Influence Factors of Mentoring. Management Review, 25, 3-5.

[21] Li, N. and Wang, X.-R. (2013) Research on Factors Affecting Tacit Knowledge Transfer in Mentoring Program. Soft Science, 27, 113-117. https://doi.org/10.5901/mjss.2013.v4n10p80

[22] Li, W. and Guo, D.Q. (2017) Research on the Appraisal Mechanism of Tacit Knowledge Transfer of Enterprise Mentoring. Information Studies: Theory \& Application, 40, 102-106.

[23] Ragins, B.R. and Scandura, T.A. (1999) Burden or Blessing? Expected Costs and Benefits of Being a Mentor. Journal of Organizational Behavior, 20, 493-509. https://doi.org/10.1002/(SICI)1099-1379(199907)20:4<493::AID-JOB894>3.0.CO;2$\underline{\mathrm{T}}$

[24] Feeney, M.K. and Bozeman, B. (2008) Mentoring and Network Ties. Human Relations, 61, 1651-1676. https://doi.org/10.1177/0018726708098081 
[25] Ellemers, N., De Gilder, D. and Haslam, S.A. (2004) Motivating Individuals and Groups at Work: A Social Identity Perspective on Leadership and Group Performance. Academy of Management Review, 29, 459-478. https://doi.org/10.5465/amr.2004.13670967

[26] Han, Y. and Yang, B.Y. (2012) The Master-Apprentice Relationship Opening the Door to the Success of the Apprentice in Career: An Analysis from the Viewpoint of the Political Technology. Management Word, No. 6, 124-132.

[27] Carter, J.W. and Youssef-Morgan, C.M. (2019) The Positive Psychology of Mentoring: A Longitudinal Analysis of Psychological Capital Development and Performance in a Formal Mentoring Program. Human Resource Development Quarterly, 30, 383-405. https://doi.org/10.1002/hrdq.21348

[28] Hassan, A.I., Baharom, M.N. and Mutalib, R.A. (2017) Social Capital and Career Advancement of Female Academic Staff in Nigerian Universities. Journal of Management Development, 36, 525-541. https://doi.org/10.1108/JMD-05-2016-0069

[29] Direnzo, M.S., Weer, C.H. and Linnehan, F. (2013) Protégé Career Aspirations: The Influence of Formal e-Mentor Networks and Family-Based Role Models. Journal of Vocational Behavior, 83, 41-50. https://doi.org/10.1016/j.jvb.2013.02.007

[30] Dong, Y., Wei, J. and Li, M. (2014) The Influence of Mentor Network to New Employees' Career Success. 2014 International Conference on Management Science \& Engineering 21 st Annual Conference Proceedings, Helsinki, Finland, 17-19 August 2014, 1064-1069. https://doi.org/10.1109/ICMSE.2014.6930346

[31] Kim, K.M.J. (2007) Mentoring Network and Self-Monitoring Personality. Management Revue, 18, 42-54. https://doi.org/10.5771/0935-9915-2007-1-42

[32] Decastro, R., Sambuco, D., Ubel, P.A., Stewart, A. and Jagsi, R. (2013) Mentor Networks in Academic Medicine: Moving beyond a Dyadic Conception of Mentoring for Junior Faculty Researchers. Academic Medicine. Journal of the Association of American Medical Colleges, 88, 488-496. https://doi.org/10.1097/ACM.0b013e318285d302

[33] Lee, D.Y. (2013) The Role of Attachment Style in Building Social Capital from a Social Networking Site: The Interplay of Anxiety and Avoidance. Computers in $\mathrm{Hu}$ man Behavior, 29, 1499-1509. https://doi.org/10.1016/j.chb.2013.01.012

[34] Bozionelos, N. and Wang, L. (2006) The Relationship of Mentoring and Network Resources with Career Success in the Chinese Organizational Environment. The International Journal of Human Resource Management, 17, 1531-1546. https://doi.org/10.1080/09585190600878345

[35] Viator, R.E. and Dalton, D. (2011) Eight Ways to Expand Your Mentoring Network: Informal Relationships Can Help at All Career Levels. Journal of Accountancy, 212, 44.

[36] Gayle Baugh, S., Dobrow, S.R. and Higgins, M.C. (2005) Developmental Networks and Professional Identity: A Longitudinal Study. Career Development International, 10, 567-583. https://doi.org/10.1108/13620430510620629 